\title{
A Tribute to Prof. E.C. Subbarao
}

I am delighted that the Transactions, Indian Institute of Metals, is bringing out a special issue of the journal to celebrate Subbarao's 90th birthday. It is difficult to believe that Subbarao is 90 . He has had fine innings lasting many decades. I and my family enjoyed having him and his wonderful wife, Kamala, as friends. My sincere wish is that he continues to be happy, keeping busy. Let me briefly recount the Subbarao I know.

Prof. E.C. Subbarao and myself met in the early 1960s at the IIT Kanpur campus. Both of us joined IIT Kanpur with high expectations of building an outstanding centre for higher education in science and technology, which would carry out research in frontier areas. I was in the chemistry department and Subbarao in the metallurgy department. Subbarao was responsible to create the Materials Science Programme at IIT/K. I recollect the enthusiasm with which many of us contributed to the programme. Note that IIT/K was the first institute in the country to talk of materials science education and the first institute to start an M.Tech. programme in this area. We had an international conference on materials science education in those early days. It was really a wonderful experience to teach in the materials programme and to guide research students.

Subbarao was heavily involved in policy making and administration in IIT/K. He was the first dean of faculty and I worked with him closely. I was the dean of research and development at that time. In everything he did, Subbarao showed his strong commitment to the institute and to the country as a whole. He was in IIT in spite of attractive alternatives available to him elsewhere. This was true of many others as well, but Subbarao's was a special case. He was already in a good position in Westinghouse laboratories in the USA and left that position to come to IIT Kanpur. It was in Westinghouse that he started publishing papers on oxides and dielectrics, some of which have become classics.

Subbarao has worked on a variety of materials with novel properties and structures. We have published a couple of papers together. He has been recognized by his election to various academies in the country. Subbarao had close links with industries for joint $R \& D$ as well as for sponsored research. When he eventually left IIT Kanpur, he decided to go to the Tata Research Development and Design Centre in Pune which he has built from the beginning. He was the founding Director of this Centre. Subbarao's commitment to IIT Kanpur, higher education as well as science and technology in the country is truly of a high order. His love for IIT Kanpur comes out clearly in the book that he wrote entitled "Eye for Excellence" which traces the early history of IIT Kanpur. I have no doubt that his contributions to IIT Kanpur were of great value and have been appreciated by all concerned.

I am delighted that Subbarao has decided to live in India. I wish him many years of happiness and productive life.

\section{N. R Rao}

Jawaharlal Nehru Centre for Advanced Scientific Research Bangalore 560 064, India

Publisher's Note Springer Nature remains neutral with regard to jurisdictional claims in published maps and institutional affiliations. 